University of Nebraska - Lincoln

DigitalCommons@University of Nebraska - Lincoln

\title{
Economic Effects of Horn Fly (Diptera: Muscidae) Populations on Beef Cattle Exposed to Three Pesticide Treatment Regimes
}

Jerome Hogsette

USDA-ARS

David Prichard

USDA-ARS

Joseph Ruff

USDA-ARS

Follow this and additional works at: https://digitalcommons.unl.edu/usdaarsfacpub

Part of the Agricultural Science Commons

Hogsette, Jerome; Prichard, David; and Ruff, Joseph, "Economic Effects of Horn Fly (Diptera: Muscidae) Populations on Beef Cattle Exposed to Three Pesticide Treatment Regimes" (1991). Publications from USDA-ARS / UNL Faculty. 1002.

https://digitalcommons.unl.edu/usdaarsfacpub/1002

This Article is brought to you for free and open access by the U.S. Department of Agriculture: Agricultural Research Service, Lincoln, Nebraska at DigitalCommons@University of Nebraska - Lincoln. It has been accepted for inclusion in Publications from USDA-ARS / UNL Faculty by an authorized administrator of DigitalCommons@University of Nebraska - Lincoln. 


\title{
Economic Effects of Horn Fly (Diptera: Muscidae) Populations on Beef Cattle Exposed to Three Pesticide Treatment Regimes
}

\author{
JEROME A. HOGSETTE, DAVID L. PRICHARD,$^{1}$ AND JOSEPH P. RUFF ${ }^{2}$ \\ USDA-ARS, Medical and Veterinary Entomology Research Laboratory, \\ P.O. Box 14565, Gainesville, Florida 32604
}

\begin{abstract}
J. Econ. Entomol. 84(4): 1270-1274 (1991)
ABSTRACT Horn flies could not be maintained below 50 per animal with sprays or dusts during a 21-wk study. However, weights of cows and calves and condition scores of cows were not influenced by suppression of Haematobia irritans (L.) populations. Results show that cattle in northwest Florida can tolerate average populations of $\geq 200$ flies for $70 \mathrm{~d}$ with no adverse economic effects. Spray treatments providing the best fly control were Lintox-D and Ra-Vap. The most economical products for use were Del-Tox, Lintox-D, and Ra-Vap.
\end{abstract}

KEY WORDS Insecta, Haematobia irritans, control, economics

Pesticide-IMPREgnated ear tags continue to be a popular choice for control of horn flies, Haematobia irritans (L.), on cattle, despite concomitant resistance development. When first introduced commercially, tags kept horn fly populations far below the economic injury level of 50 per animal (Butler 1975) for several months (Ahrens \& Cocke 1979, Knapp \& Herald 1981, Williams et al. 1981, Miller et al. 1984). However, horn flies soon became resistant to stirofos and pyrethroids, and ear tags are no longer recommended for use in horn fy management programs in some parts of the United States (Sheppard 1983, 1984; Harvey et al. 1984; Quisenberry et al. 1984; Kunz \& Schmidt 1985; Schmidt et al. 1985).

Suggested solutions to the horn fly resistance problem include the use of sprays and dust bags, alternation or rotation of pesticides, and (notably) maintenance of fly populations within economically tolerable levels (Sheppard \& Hinkle 1985, Sparks et al. 1985). Although economic injury levels have not been well defined nationwide, levels of 200 or more flies per animal (Haufe 1979, Schreiber et al. 1987) might be more realistic than 50 , and make the degree of horn fly suppression expected with ear tags (i.e., $\approx 100 \%$ ) completely unnecessary.

The purpose of our study was to determine the feasibility of maintaining horn fly populations below 50 flies per animal on small herds of pastured beef cattle without using ear tags. Registered pes-

\footnotetext{
This article reports the results of research only. Mention of a proprietary product or a pesticide does not constitute an endorsement or a recommendation for its use by USDA or the State of Florida, nor does it imply registration under FIFRA as amended.

${ }^{1}$ N. Florida Research and Education Center, Rt. 3, Box 4370, Quincy, Fla. 32351.

Dog Fly Control, 3920 Frankford Ave, Panama City, Fla. 32405 .
}

ticides were applied as sprays and dusts in a predetermined rotation schedule. Because horn fly resistance to pyrethroids has been reported in Florida (Kunz \& Schmidt 1985, Hogsette \& Ruff 1986), none was used in this study. Cow and calf weights and cow condition scores were used as indicators of the economic damage.

\section{Materials and Methods}

Animals consisted of 85 cow-calf pairs and 20 yearling heifers of mostly Angus or Brangus breeding pastured at the University of Florida Beef Demonstration Unit, a 63.8-ha facility in Chipley, Washington County, Fla. Cattle were stratified by age, color, and herd origin into four treatment groups, and treatments were assigned to the groups at random. The design is summarized in Table 1.

Treatment 1 consisted of application of pesticides by forced-use dust bags to both cows and calves. Mineral boxes in each pasture were placed in fenced enclosures large enough to comfortably accommodate one treatment group. A dust bag station (Hogsette et al. 1988) was constructed at the entrance of each enclosure, but dust bags were hung only in the station used by cows and calves that received treatment 1 . When cattle that received treatment 1 were moved to a different pasture, the dust bags were also moved to the same pasture. Cattle that received treatment 2 were not treated with any pesticides, but were managed like the other treatment groups.

Treatment 3 consisted of registered pesticides applied to cows and calves at the minimum treatment interval designated on the pesticide labels. Treatment 4 consisted of registered pesticides applied to cows and calves only when the average weekly horn fly count exceeded 50 flies per head. However, time between applications was never less 
Table 1. Experimental design for cow-calf experiments performed at the Chipley Beef Demonstration Unit in $\mathbf{1 9 8 6}$

\begin{tabular}{clccc}
\hline \hline \multirow{2}{*}{$\begin{array}{c}\text { Treat- } \\
\text { ment } \\
\text { number }\end{array}$} & Treatment & \multicolumn{3}{c}{ Animals } \\
\cline { 3 - 4 } & & $\begin{array}{c}\text { Cow- } \\
\text { calf } \\
\text { pairs }\end{array}$ & $\begin{array}{c}\text { Year- } \\
\text { ling } \\
\text { heifers }\end{array}$ & Total \\
\hline 1 & Forced-use dust bags & 23 & 4 & 50 \\
2 & Untreated control & 21 & 5 & 47 \\
3 & Spray as often as allowed & 21 & 5 & 47 \\
4 & $\begin{array}{l}\text { Spray when tlies >50 } \\
\text { per head }\end{array}$ & 20 & 6 & 46 \\
Total & & & & 190 \\
\hline
\end{tabular}

than the minimum treatment interval stated on the pesticide label.

Registered pesticides were used (Table 2) in a predetermined rotational schedule so that each pesticide applied was in a different class or different group within a class from the pesticide previously applied. Pesticides were chosen for their availability in the southeastern United States, except for methoxychlor emulsifiable concentrate (EC), the only pesticide used that was not from the organophosphorus class. Methoxychlor EC was purchased directly from the parent company because of its limited use in the eastern states.

The first and last pesticide applications were made on 23 June and 17 November 1986, respectively. Calves were weighed on 16 June, 11 August, and 13 October, and then weaned and removed from the study. Cows were weighed and then condition scored by D.L.P. on the above dates, and on 24 November 1986, when the study was terminated. The condition score is a visual measure of the degree of emaciation or fatness of an animal (Kunkle \& Sand 1990).

Treatment groups were kept in noncontiguous pastures and rotated to a different pasture weekly to minimize the effects of forage quality and quantity. Pastures ranged from 2.9 to 10.5 ha $(\bar{x}=6.4$ ha) and consisted of annual and perennial improved forages. Water and minerals were provided free-choice. Untreated cattle pastured on property adjoining the eastern perimeter of the Beef Demonstration Unit ensured that high horn fly pressure was maintained throughout the treatment area.
Horn flies visible on one side of 10 adult animals per treatment group were counted on 19 June (pretreatment count) and at 2-wk intervals thereafter between 0900 and 1100 hours by J.P.R. (Koehler \& Butler 1977). Unofficial fly counts (not used in analyses) were made weekly by Beef Demonstration Unit personnel. Decisions to apply pesticides to treatment group 4 were made by J.P.R. after conferring with Beef Demonstration Unit personnel. Horn flies were the only serious fly pest on these cattle. Stomoxys calcitrans (L.) populations averaged one fly per animal during the study period.

Weight and condition score data were analyzed by method of least squares analysis of variance (Damron \& Harvey 1987) using General Linear Models (GLM) Procedures (SAS Institute 1985). Orthogonal contrasts were used to make the following mean comparisons of the dependent variables: between spray treatment regimes (treatment 3 versus treatment 4), between dust bag treatment and both spray treatment regimes (treatment 1 versus treatment 3 and 4 ), and between all pesticide treatments and the control group. Mathematical models for cows and calves included cow number, breed, treatment, and weigh period; and calf number, breed, treatment, sex, and weigh period, respectively. Fly data were analyzed with GLM Procedures (SAS Institute 1985). Mathematical models for fly numbers included treatment and replication. Unless otherwise stated, $P=0.05$. Evaluations of spray formulations were based on their fly control efficacy.

\section{Results and Discussion}

Preliminary comparisons of cow regression curves indicated a significant difference in condition scores attributable to breed $(F=2.82 ; \mathrm{df}=3,309)$, treatment $(F=5.75$; $\mathrm{df}=9,303)$, and breed-treatment interaction $(F=3.09 ; \mathrm{df}=21,291)$. Orthogonal contrasts showed that effects of treatments 3 and 4 on condition score differed significantly $(F=3.69$; $\mathrm{df}=3,150$ ). There was also a significant difference between the groups treated with pesticide and the control group ( $F=2.48 ; \mathrm{df}=3,309)$, and between the group treated with dust bags and the spraytreated groups $(F=9.74 ; \mathrm{df}=3,231)$. However,

Table 2. Residual periods and costs of emulsifiable concentrates most often used for treatments 3 and 4 of the 1986 cow-calf experiments at the Chipley Beef Demonstration Unil

\begin{tabular}{|c|c|c|c|c|c|}
\hline $\begin{array}{l}\text { Commercial } \\
\text { name }\end{array}$ & Manufacturer & Formulation & $\begin{array}{c}\text { Minimum } \\
\text { treatment } \\
\text { interval, } \\
\text { wk (label) }\end{array}$ & $\begin{array}{c}\text { Efficacy } \\
\text { period, wk } \\
\text { (observed) }\end{array}$ & $\begin{array}{c}\text { Cost/ } \\
\text { hend// } \\
\mathbf{w k}^{a}\end{array}$ \\
\hline Lintox-D & Starbar, Dallas, Tex. & dioxathion $10.5 \%$, vapona $0.5 \%$ & 2 & 4 & 0.17 \\
\hline Ra-Vap & Biotech Corp., Painesville, Ohio & rabon $23.0 \%$, vapona $5.7 \%$ & 1 & 3 & 0.50 \\
\hline Co-Ral & Mobay Corp. Shawnee, Kans. & coumaphos $11.6 \%$ & none & 1 & 0.31 \\
\hline Methoxychlor & Hopkins Ag. Chemicals, Madison, Wis. & methoxychlor $24.8 \%$ & 2 & 2 & 0.19 \\
\hline Prolate & Starbar. Dallas. Tex. & phosmet $11.6 \%$ & 1 & 1 & 0.26 \\
\hline Del-Tox & Cooper Animal Health, Kansas City, Mo. & dioxathion $20.4 \%$ & 2 & 2 & 0.13 \\
\hline
\end{tabular}

a Based on treatment interval stated on label; application rate, $\approx 3.8$ liters per head. Labor and treatment costs are not included. 


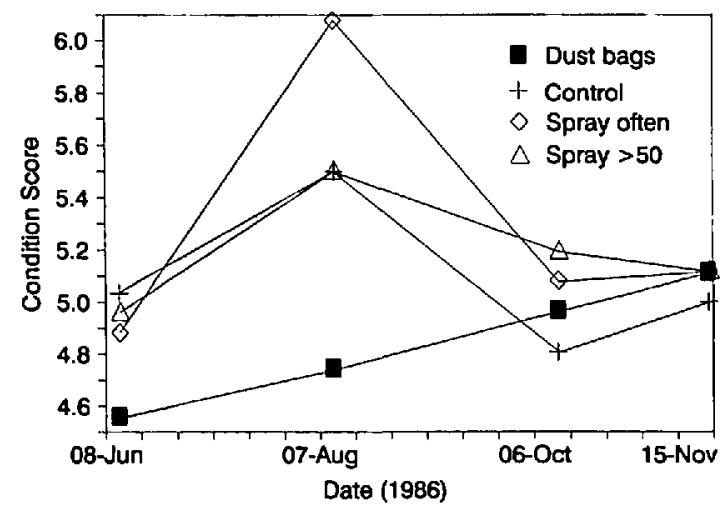

Fig. 1. Condition score curves for cows treated with dust bags and two spray regimens for control of horn flies.

these differences proved to be inconsequential because, despite differences in the shapes of the curves (Fig. 1), the final condition scores were not significant $(F=0.85$; $\mathrm{df}=3$ ).

Preliminary comparisons of regression curves for cow weight indicated that breed difference was not significant $(F=1.29 ; \mathrm{df}=3,309)$ and that treatment differences $(F=6.27$; $\mathrm{df}=9,303)$ and breed-treatment interactions $(F=3.09$; df $=21,291)$ were significant. Orthogonal contrasts showed no difference in weight due to either spray treatment ( $F$ $=2.21 ; \mathrm{df}=3,150)$, or to any of the pesticide treatments $(F=2.38$; $\mathrm{df}=3,309)$. Differences between the dust bag treatment and the two spray treatments were significant $(F=9.56$; df $=3,321)$ but, again, inconsequential because differences in the final weights were not significant $(F=0.22$; df $=3$ ). Differences in curve shape (Fig. 2) again accounted for the significant breed-treatment interaction associated with weight.

Preliminary comparisons of regression curves for calf weight indicated no significant difference attributable to breed $(F=1.88 ; \mathrm{df}=2,166)$ or treatment ( $F=1.0$; df $=6,162)$ (Fig. 3). Orthogonal contrasts showed that weight was not affected by

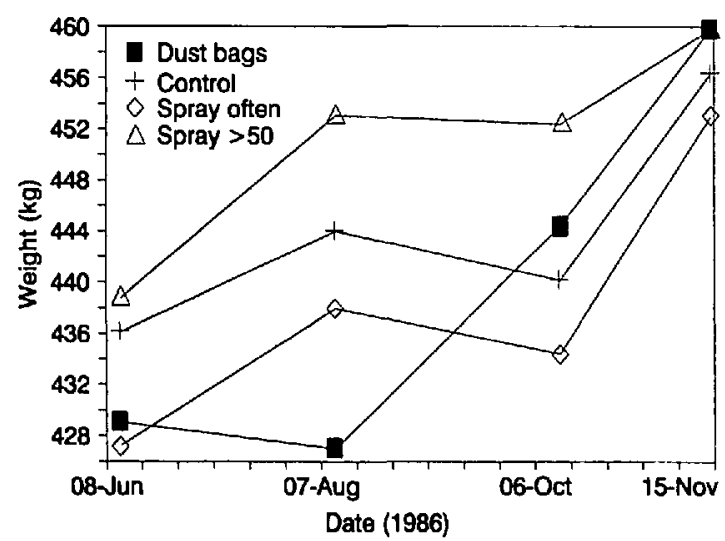

Fig. 2. Weight curves for cows treated with dust bags and two spray regimens for control of horn flies.

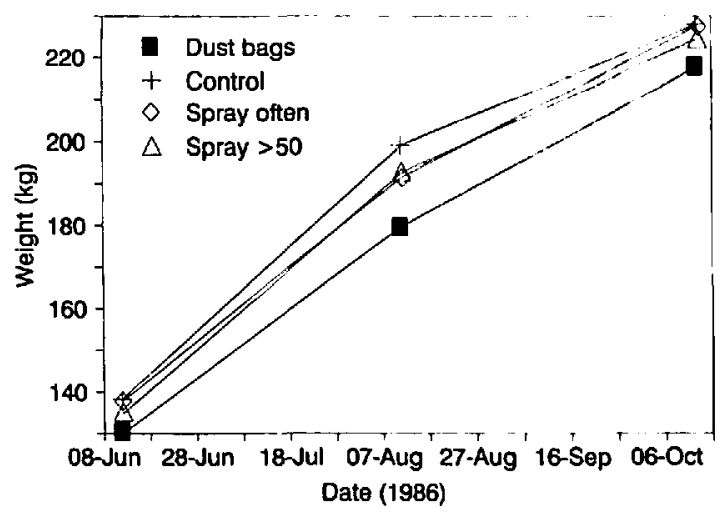

Fig. 3. Weight curves for calves treated with dust bags and two spray regimens for control of horn ties.

either of the two spray treatments $(F=0.37$; $\mathrm{df}=$ 2,78 ), by either the dust bag treatment or the spray treatments $(F=1.05 ; \mathrm{df}=2,124)$, or by any of the three pesticide treatments $(F=1.71 ; \mathrm{df}=2,166)$.

Horn flies could not be maintained below 50 per animal (25 per side) with either sprays or dust (Fig. 4), but treatment populations were usually lower than the control population. Applying pesticides as often as permitted (treatment 3 ) best suppressed flies during the fall population increase (1 August12 September); however, this required almost weekly pesticide applications. Withholding treatment until fly populations exceeded 50 per animal and being limited to the 7-d treatment interval imposed by the experimental design actually decreased the chances of keeping flies under control. Spraying at 7-d intervals coincided well with the residual periods of the pesticides (Table 2), but potentially allowed large fluctuations in fly populations. If $\oplus$ ly populations averaged $<50$ on treatment group 4 on the day they could be sprayed

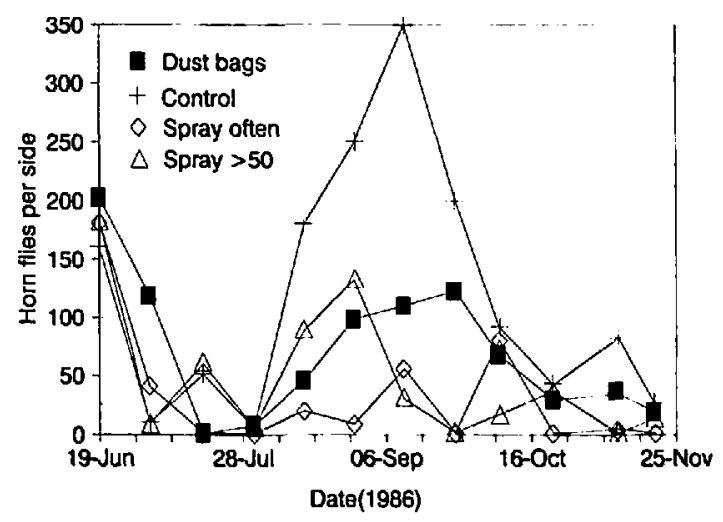

Fig. 4. Mean horn fly populations per side on cows and yearling heifers used in the 1986 cow-calf experiments at the Chipley Beef Demonstration Unit. Dotted lines represent the 50 and 200 flies per animal (25 and 10 tlies per side) economic injury levels suggested by Butler (1975), Haufe (1979), and Schreiber et al. (1987), respectively. 
(which means they would not be sprayed), and averaged $>50$ on the next day, populations then had six additional days to increase to even higher levels before the next pesticide was applied. Fly populations were generally higher on the dust bag group than on either spray group. This was particularly interesting because most dust bag stations were shaded and used daily by cattle for loafing areas.

Lintox-D (delnav $10.5 \%$ + vapona $0.5 \%$; Starbar, Dallas, Tex.) and Ra-Vap (rabon $23.0 \%$ + vapona 5.3\%; S.D.S. Biotech Corp., Painesville, Ohio) provided the best results of the six emulsifiable concentrates used most often (Table 2). When pesticides were applied as often as permitted (treatment 3), Deltox (delnav 20.4\%; Cooper Animal Health, Kansas City, Mo.) was the least expensive to use (Table 2). However, the extended residual activity observed with Lintox-D and Ra-Vap made these pesticides no more expensive than Deltox.

Cow condition score and weight curves resulting from the dust bag treatment differed significantly from all other curves produced for these two variables. For unknown reasons, weight and condition score of the dust bag group decreased numerically between weigh periods 1 and 2 and increased numerically between weigh periods 2 and 3 , whereas the other groups did just the opposite (Fig. 1 and 2). However, differences in final values for weight and condition score were not significant.

Calf weight curves were closely grouped and did not differ significantly (Fig. 3), i.e., no significant difference in weight attributable to treatment was detected. This agrees with the data of Gerhardt \& Shrode (1990) and Schreiber et al. (1987), but disagrees with those of Kunz et al. (1984), Quisenberry \& Strohbehn (1984), Campbell (1976), Harvey \& Brethour (1979), and Haufe (1979, 1982, 1986). Flies exceeded 200 per head on the control group for $\approx 10 \mathrm{wk}$, but weight was not negatively influenced. In fact, mean weight of the calf control group was numerically more than that of the pesticide-treated groups during the entire study (Fig. 3). This suggests that the economic injury level (i.e. the number of flies over time necessary to suppress weight gains) in northwest Florida is much higher than 200 flies per head for $70 \mathrm{~d}$, or more than seventy $200+$ fly days. The possibility that weight gains may have been suppressed by marginal pesticide toxicity (Haufe 1973) in treatment groups 3 and 4 might be suspected if the mean weights for these groups had been lower than those of the dust bag group. However, this was not the case (Fig. 3).

Haufe (1979) indicated that cattle can compensate for fly populations if rate of increase is not too rapid and if high quality forage is available. If our cattle suffered temporary weight losses which were compensated for before the end of the study, losses were short term and could not be detected with our weighing intervals. Also, ample forage was available throughout our study, a factor which varies greatly with geographical location. Haufe (1986) also suggested that mature cattle show an increased tolerance to flies with age, and that reductions in growth occur when the immunological and metabolic systems are stressed by extremely high fly populations. In Florida, horn fly populations exist year-round (Butler et al. 1981), and cattle are exposed continuously except for intermittant periods when pesticide treatments are being used. Therefore, cattle in geographic areas with comparatively long fly seasons would probably develop higher fly tolerance thresholds than cattle in areas where fy seasons are relatively short.

In summary, we were unable to maintain horn flies below a level of 50 tiles per animal on cowcalf pairs in northwest Florida. Fly populations were effectively reduced, but this reduction did not significantly influence cow and calf weights and cow condition score. Data indicate that the economic injury level exceeds seventy $200+$ fly days. Neither of our spray regimens would be practical for commercial use, especially with no indication of increased net returns. Less strenuous regimens would certainly be counterproductive. Dust bags produced no positive results but would be less labor-intensive than spraying if some degree of horn fly control is desired.

The fact that pesticide treatments did not affect weight gains in a positive manner was unexpected. However, this finding might prove beneficial to horn fly resistance management. If cattle can be produced economically by managing instead of eliminating horn flies, this will result in less pesticide use and less selection pressure on horn fly populations.

\section{Acknowledgment}

We are indebted to C. J. Wilcox, University of Florida, for his invaluable advice on least squares analysis. We thank J. Clemmons and R. Crutchfield (University of Florida Beef Demonstration Unit) for maintenance of cattle and application of pesticides. We also thank J. B. Campbell (University of Nebraska), C. J. Jones (University of Illinois), S. E. Kunz (USDA-ARS, Kerrville, Tex.), and C. D. Steelman (University of Arkansas) for their critical reviews of this manuscript.

\section{References Cited}

Ahrens, E. H. \& J. Cocke. 1979. Season long horn fly control with an insecticide-impregnated ear tag. J. Econ. Entomol. 72: 215.

Butler, J. F. 1975. Economics and control of livestock insects, pp. 143-152. In Proceedings, FAO/IAEA training course on use of radioisotopes and radiation in entomology, Gainesville, Fla.

Butler, J. F., R. Escher \& J. A. Hogsette. 1981. Natural parasite levels in house flies, stable flies, and horn flies in Florida, pp. 61-79. In Status of biological control of filth fies. Proceedings of a workshop. ARS/ USDA, University of Florida, Gainesville.

Campbell, J. B. 1976. Effect of horn fly control on cows as expressed by increased weaning weights of calves. J. Econ. Entomol. 69: 711-712. 
Damron, R. A., Jr. \& W. R. Harvey. 1987. Experimental design, ANOVA, and regression. Harper \& Row, New York.

Gerhardt, R. R. \& R. R. Shrode. 1990. Influence of face and horn fly control on weight gain in pastured cow-calf groups. J. Agric. Entomol. 7: 11-15.

Harvey, T. L. \& J. R. Brethour. 1979. Effect of horn flies on weight gains of beef cattle. J. Econ. Entomol. 72: 516-518.

Harvey, T. L., J. R. Brethour \& A. B. Broce. 1984. Loss in effectiveness of insecticide ear tags for horn fly (Diptera: Muscidae) control. J. Kans. Entomol. Soc. 57: 715-717,

Haufes W. O. 1973. Interaction of pesticidal toxicity, parasites, and reversible anticholinesterase activity as stresses on growth rate in cattle infested with horn flies Haematobia irritans L. Toxicol. Appl. Pharmacol. 25: 130-144.

1979. Reduced productivity of beef cattle infested with horn flies. Agriculture Canada Research Station. 1978 Research Highlights: 61-63.

1982. Growth of range cattle protected from flies (Haematobia irritans) by ear tags impregnated with fenvalerate. Can. J. Anim. Sci. 62: 567-573.

1986. Productivity of the cow-calf unit in range cattle protected from horn flies, Haematobia irritans (L.) by pesticidal ear tags. Can. J. Anim. Sci. 66: 575-589.

Hogsette, J. A. \& J. P. Ruff. 1986. Evaluation of flucythrinate- and fenvalerate-impregnated ear tags and permethrin ear tapes for fly (Diptera: Muscidae) control on beef and dairy cattle in northwest Florida. J. Econ. Entomol. 79: 152-157.

Hogsette, J. A., D. L. Prichard, J. P. Ruff \& P. G. Koehler. 1988. Self-treatment for livestock: dust bags. Florida Cooperative Extension Service Livestock Protection Pointer No. 5 (Revised April, 1988).

Knapp, F. W. \& F. Herald. 1981. Face fly and horn fly reduction on cattle with fenvalerate ear tags. J. Econ. Entomol. 74: 295-296.

Koehler, P. G. \& J. F. Butler. 1977. Control of external parasites with forced-use dustbags. Florida Cooperative Extension Service Livestock Protection Pointer No. 12.

Kunkle, W. E. \& R. S. Sand. 1990. Good body condition improves rebreeding. Fla. Cattleman 54(10): $46-48$.

Kunz, S. E. \& C. D. Schmidt. 1985. The pyrethroid resistance problem in the horn fly. J. Agric. Entomol. 2: 358-363

Kunz, S. E., J. A. Miller, P. L. Sims \& D. C. Meyer- hoffer. 1984. Economics of controlling horn flies (Diptera: Muscidae) in range cattle management. J. Econ. Entomol. 77: 657-660.

Miller, R. W., R. D. Hall, F. W. Knapp, R. E. Williams, K. E. Doisey, F. Herald \& C. A. Towell. 1984. Permethrin ear tags evaluated in four states for control of the horn fly and face fly. J. Agric. Entomol. 1: 264-268.

Quisenberry, S. S. \& D. R. Strohbehn. 1984. Horn Fly (Diptera: Muscidae) control on beef cows with permethrin-impregnated ear tags and effect on subsequent calf weight gains. J. Econ. Entomol. 77.: 422424.

Quisenberry, S. S., J. A. Lockwood, R. L. Byford, H. K. Wilson \& T. C. Sparks. 1984. Pyrethroid resistance in the horn fly, Haematobia irritans (L.)(Diptera: Muscidae) J. Econ. Entomol. 77: 10951098.

SAS Institute. 1985. SAS user's guide: statistics. SAS Institute, Cary, N.C.

Schmidt, C. D., S. E. Kunz, H. D. Petersen \& J. L. Robertson. 1985. Resistance of horn flies (Diptera Muscidae) to permethrin and fenvalerate. J. Econ. Entomol. 78: 402-406.

Schreiber, E. T., J. B. Campbell, S. E. Kunz, D. C. Clanton \& D. B. Hudson. 1987. Effects of horn fly (Diptera: Muscidae) control on cows and gastrointestinal worm (Nematode: Trichostrongylidae) treatment for calves on cow and calf weight gains. J. Econ. Entomol. 80: 451-454.

Sheppard, D. C. 1983. Stirophos resistance in a population of horn flies. J. Ga. Entomol. Soc. 18: 370377.

1984. Fenvalerate and flucythrinate resistance in a horn fly population. J. Agric. Entomol. 1: 305-310.

Sheppard, D. C. \& N. C. Hinkle. 1985. Pyrethroid resistance in horn lies: the problem, causes, and possible solutions. J. Agric. Entomol. 2: 317-324.

Sparks, T. C., S. S. Quisenberry, J. A. Lockwood, R. L. Byford \& R. T. Roush. 1985. Insecticide resistance in the horn $\mathrm{Hy}$, Haematobra irritans. J. Agric. Entomol. 2: 217-233.

Williams, R. E., E. J. Westby, K. S. Hendrix \& R. P. Lemenager. 1981. Use of insecticide-impregnated ear tags for the control of face flies and horn flies on pastured cattle. J. Anim. Sci. 53: 1159-1165.

Received for publication 30 November 1990; accepted 20 March 1991 